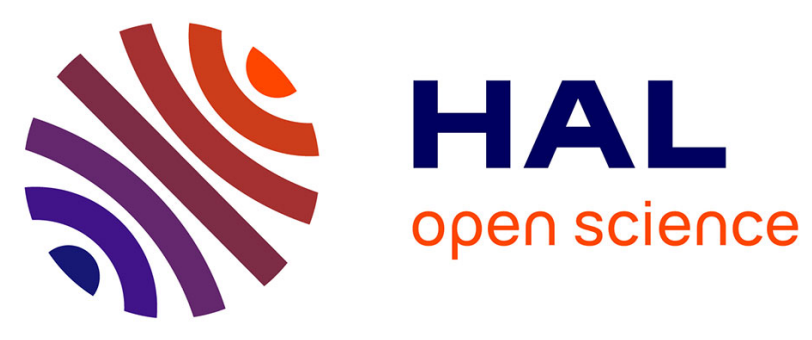

\title{
Identification of a cohesive zone model for cement paste-aggregate interface in a shear test
}

Nesrine Salah, Mouad Jebli, Etienne Malachanne, Frédéric Jamin, Frédéric Dubois, A. S. Caro-Bretelle, Eric Garcia-Diaz, Moulay Saïd El Youssoufi

\section{- To cite this version:}

Nesrine Salah, Mouad Jebli, Etienne Malachanne, Frédéric Jamin, Frédéric Dubois, et al.. Identification of a cohesive zone model for cement paste-aggregate interface in a shear test. European Journal of Environmental and Civil Engineering, 2019, pp.1-15. 10.1080/19648189.2019.1623082 . hal-02153545

\section{HAL Id: hal-02153545 \\ https://hal.science/hal-02153545}

Submitted on 12 Jun 2019

HAL is a multi-disciplinary open access archive for the deposit and dissemination of scientific research documents, whether they are published or not. The documents may come from teaching and research institutions in France or abroad, or from public or private research centers.
L'archive ouverte pluridisciplinaire HAL, est destinée au dépôt et à la diffusion de documents scientifiques de niveau recherche, publiés ou non, émanant des établissements d'enseignement et de recherche français ou étrangers, des laboratoires publics ou privés. 


\title{
Identification of a cohesive zone model for cement paste-aggregate interface in a shear test
}

\author{
Salah Nesrine ${ }^{a, b}$, Jebli Mouad ${ }^{b, c}$, Malachanne Etienne ${ }^{a}$, Jamin Frédéric ${ }^{b, c}$, \\ Dubois Frédéric $^{b, c}$, Caro Anne-Sophie ${ }^{a}$, Garcia-Diaz Eric ${ }^{a}$ and \\ El Youssoufi Moulay Saïd ${ }^{b, c}$ \\ ${ }^{a}$ C2MA, IMT Mines Alès, Alès, France; ${ }^{b}$ LMGC, Univ. Montpellier, CNRS, Montpellier, France; ${ }^{c}$ MIST Lab., IRSN, \\ CNRS, Univ, Montpellier, France
}

\begin{abstract}
The development of tools, using a micromechanical approach, predict-ing the macroscopic behaviour of heterogeneous materials such as con-crete, requires the knowledge of their microstructures (geometrical properties of phases), the behaviour of phases and the interaction laws between phases. This study is focused on a numerical modelling of a local shear test on a cement paste-aggregate composite using a cohe-sive zone model with the objective to identify the behaviour of the cement paste-aggregate interface. The computations use a 3D finite element modelling of the composite, using a cohesive law at the inter-face between the two phases. The cohesive model mimics the behav-iour of the well-known interfacial transition zone. This work presents a methodology for the identification of cohesive law parameters at differ-ent stages of hydration and for different confining stresses using experi-mental results.
\end{abstract}

\section{Introduction}

The prediction of the mechanical behaviour of concrete under various loads, as well as the service life evaluation of concrete structures, are scientific questions that interrogate the researchers and the engineers. It implies multiple scientific impediments and challenges. The behaviour of concrete, a porous and multiphasic material, with regard to extreme mechanical and environmental stress, should be understood through multi-physical and multi-scale approaches. According to Wittmann's classification (Wittmann, 1983), concrete behaviour can be considered on macroscopic, mesoscopic or microscopic scales. Different types of input parameters are considered for each of these scales.

At the macroscopic scale the effective mechanical properties are related to the phases properties and in particular, those of the cement paste-aggregate interfaces. In fact, the presence of aggregates modifies the microstructure of the cement paste by introducing a thin interface between the aggregates and the cement matrix. Different denominations are used to define this zone, among them one finds interfacial transition zone (Diamond, Mindess, \& Lovell, 1982; Ollivier \& Grandet, 1982). The presence of this interface influences the overall concrete behaviour because of its weak local mechanical properties, and its strong transport properties (Lutz, Monteiro, \& Zimmerman, 1997). Several workshave examined the interface properties (Ollivier, 
Maso, \& Bourdette, 1995; Diamond, 2001; Diamond \& Huang, 2001; Erdem, Dawson, \& Thom, 2012a, 2012b; Vargas, Restrepo-Baena, \& Tobón, 2017). These studies have shown that this zone has a higher Water/Cement ratio (W/C) than the rest of the cement paste, due to a 'wall effect' and micro-bleeding effects, which makes this zone more porous and heterogeneous. To model the mechanical behaviour of concrete, it is necessary to take into account the properties of the interface (Neubauer, Jennings, \& Garboczi, 1996).

Several approaches have been developed to consider the interface as a third phase through finite element modelling (Bernard \& Kamali-Bernard, 2015; Shuguang \& Qingbin, 2015) with a higher porosity than the bulk paste (Grondin \& Matallah, 2014). In this method, the interface is represented geometrically and physically; nevertheless, the small thickness (few micrometres) of this zone raises several practical difficulties such as meshing.

In order to overcome these difficulties, conventional homogenisation methods for the threephase heterogeneous composite have been used (Zhou, Li, \& Ma, 2014; Ke, Ortola, Beaucour, \& Dumontet, 2010). However, even these analytical approaches are sufficiently accurate to determine the equivalent elastic modulus of such heterogeneous material, they are still limited to predict the non-linear part of the behaviour.

Thus, to propose a good description of the mechanical behaviour outside the linear domain, some mechanical models take into account non-linear interaction between cement paste and aggregate. Among these models, some authors have introduced a totally damaged zone between cement paste and aggregate (Keinde, Kamali-Bernard, Bernard, \& Cisse, 2014), while others have replaced interface by a localised damage (Gangnant, Saliba, La Borderie, \& Morel, 2016).

In this work, a cohesive zone model is used to take into account of the mechanical behaviour of the third phase between the cement paste and the aggregate. To avoid meshing problems the interface thickness is hidden in the interaction law which couples adhesion, friction and unilateral contact (Fremond \& Nedjar, 1996; Raous, Cangemi, \& Cocu, 1999; Talon \& Curnier, 2003; Raous, 2011). The cohesive zone models introduce a local damaging surface leading to the creation of two crack lips while extreme loadings. Incorporating cohesive models between all elements of a finite element mesh (or part of the mesh) makes possible to simulate crack initiation and propagation for a given loading path and microstructure. Cohesive zone models present many interesting perspectives in the field of numerical simulation and mechanical analysis of material fracture (Monerie \& Acary, 2001), and were used in several physical domains such as masonry structures (Bisoffi-Sauve, Morel, \& Dubois, 2019; Fouchal, Lebon, \& Titeux, 2009; Alfano $\&$ Sacco, 2006). One advantage of the cohesive zone model is its ability to model from initiation of cracks to post-rupture mechanisms such as Signorini-Coulomb frictional contact.

This study focuses on the numerical simulation of a bi-material shear test during hydration. Our simulations concern a rigorous calibration of the local parameters of the cohesive models. A previous work was carried out to identify the parameters of the cohesion law in the case of a uniaxial tensile test (Malachanne, Jebli, Jamin, Garcia-Diaz, \& El Youssoufi, 2018). In this work, we present a numerical identification strategy of the tangential cohesive response (in mode II) relying on the experimental work of Jebli, Jamin, Malachanne, Garcia-Diaz, and El Youssoufi (2018).

Identification of the local behaviour of the cement paste-aggregate interface for the two rupture modes is a prerequisite to study the concrete behaviour in case of mixed-mode loads taking into consideration such interfacial properties.

\section{Materials, experimental device and data}

\subsection{Materials}

The cement paste is prepared using Portland cement CEM II 32.5 with a Water/Cement ratio (W/ C) of 0.5 . The aggregate is a natural limestone, its dimensions are $10 \times 10 \times 15 \mathrm{~mm}^{3}$. The 
dimensions of the parallelepipedic composite (cement paste-aggregate) are $10 \times 10 \times 30 \mathrm{~mm}^{3}$. (Figure 1a). Surface saw cuts were made to provide a similar surface roughness for all aggregates. Limestone aggregates react well with the cement paste, which gives a good adhesion (Kamali-Bernard, Keinde, \& Bernard, 2014). This adhesion does not prevent the formation of a cement-aggregate interface of about $25 \mu \mathrm{m}$ visible using an electron microscopy scanning Figure 1b. The material data are presented in Table 1 and in Table 2, the Young's modulus of the cement paste is given for each time of hydration.

\subsection{Experimental device}

A specific experimental device was designed to perform the shear test on the interface. The device presented in Figure 2 consists in two half-boxes. The distance between these two halfboxes is about $0.5 \mathrm{~mm}$ in order to avoid any bending of the sample. The screws located at the rear of the half-boxes make it possible to fix the interface cement paste-aggregate in the middle of the device, thus avoiding any movements of the sample during the test and making it possible to apply a normal confining force $N$. To measure the applied normal force, a force sensor (type LCMKD-200 N) is attached to the sample rear. Figure 2a illustrates the experimental device, in which the sample is placed inside the two half-boxes (Jebli, Jamin, Malachanne, Garcia-Diaz, \& El Youssoufi, 2018). The principle of the test is to apply a constant normal compressive force $N$ during the test, inducing a confining stress $\sigma_{\mathrm{N}}$ on the $10 \times 10 \mathrm{~mm}^{2}$ interface surface (see Figure 2b). This normal force $N$ is monitored through the force sensor. During the test, the vertical displacement speed of the moving half-boxes is imposed at $0.01 \mathrm{~mm} / \mathrm{s}$, whereas the other half-box remains still and rigidly fixed in all directions. During this load, the shear force $T$ is measured by a force sensor associated to the MTS system, allowing to access to a mean shear stress $\sigma_{\mathrm{T}}$ at cement paste-aggregate interface (Jebli, Jamin, Malachanne, Garcia-Diaz, \& El Youssoufi, 2018).

For each hydration time $(2,7,15,28$ and 40 days), shear tests were carried out systematically on three samples, with recording of the force-displacement curve. In order to evaluate the displacement fields of the interface, a Vision Research Phantom V12 fast camera (acquisition rate of 10 to 40,000 frames per second) was used. This technique makes it possible to record images which are processed by digital image correlation in order to measure the displacement and the stress fields around the interface. Generally, a random texture or pattern on the surface of the samples is used. Because of the small size of the samples, it was necessary to develop a protocol for speckle, which makes it possible to obtain homogeneous small markers on the whole surface of the sample (Figure $3 \mathrm{c}$ ). This random aspect is applied by spraying a white paint on the surface of the studied sample, previously tinged in black. The two-dimensional kinematic measurements (displacement and strain) are obtained through the software 'Trait cin NRJ' developed in our laboratory (Wattrisse, Chrysochoos, Muracciole, \& Némoz-Gaillard, 2001). These markers are

(a)

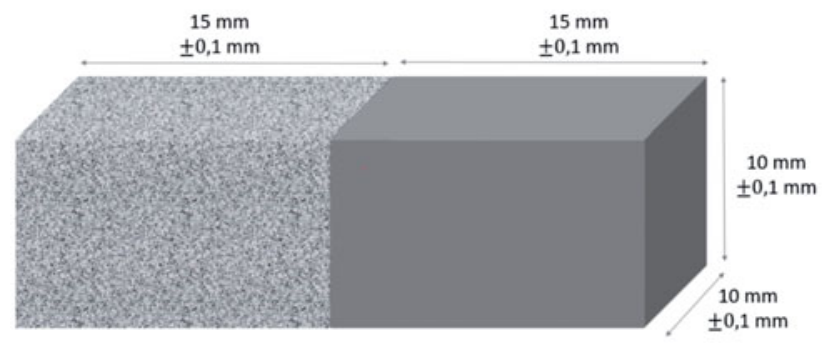

(b)

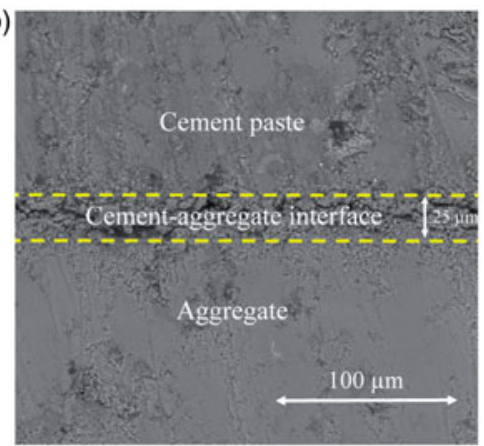

Figure 1. Dimension of the sample used in the shear test (a) and SEM observation of cement paste-aggregate interface (b). 
Table 1. Used Material data (Jebli, Jamin, Malachanne, Garcia-Diaz, \& El Youssoufi, 2018).

\begin{tabular}{lc}
\hline & Aggregate \\
\hline Type & Limestone \\
Density & $2.7 \mathrm{~g} / \mathrm{cm}^{3}$ \\
Dimension & $10 \times 10 \times 15 \mathrm{~mm}^{3}$ \\
Young's modulus & $60 \mathrm{GPa}$ \\
Poisson's ratio & 0.2 \\
\hline & Cement paste \\
\hline Formula & $\mathrm{CEM}$ II/B-LL $32.5 \mathrm{CP} 2 \mathrm{~N}$ \\
Water/cement ratio & 0.5 \\
Density & $2.2 \mathrm{~g} / \mathrm{cm}^{3}$ \\
Young's modulus (at 28-day of hydration) & $12.5 \mathrm{GPa}$ \\
Poisson ratio's & 0.2 \\
\hline
\end{tabular}

Table 2. Young's modulus of cement paste at different stages oh hydration.

\begin{tabular}{lc}
\hline Hydration time (days) & Young's modulus (GPa) \\
\hline 2 & 6.3 \\
7 & 9.3 \\
15 & 12.4 \\
28 & 12.5 \\
40 & 12.5 \\
\hline
\end{tabular}

(a)

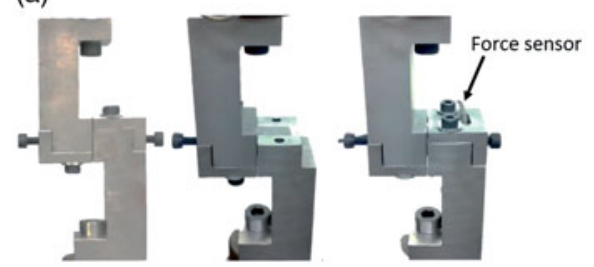

(b)

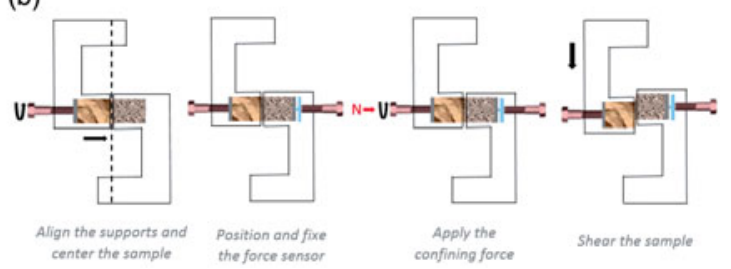

Figure 2. Experimental device for the shear test on cement-aggregate interface (a) and the principle of the direct shear test (b) (Jebli, Jamin, Malachanne, Garcia-Diaz, \& El Youssoufi, 2018).

(a)

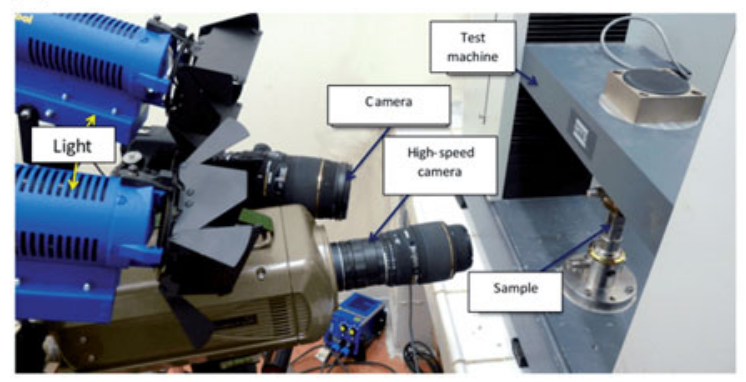

(b)

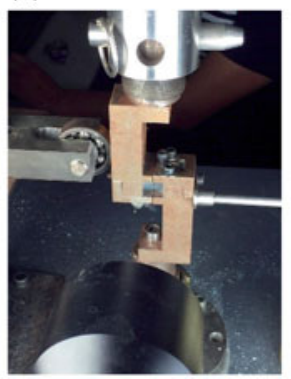

(c)

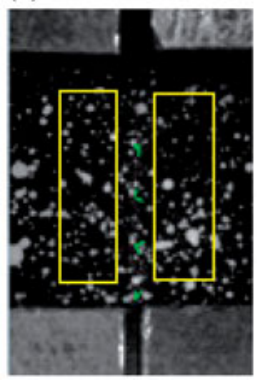

Figure 3. Experimental devices for image correlation (a) and (b) and displacement calculation zones by image correlation for the shear test (c) (Jebli, Jamin, Malachanne, Garcia-Diaz, \& El Youssoufi, 2018).

positioned on the material whose successive positions are analysed with respect to a reference time. Thus, by comparing two images taken at different loading levels, it is possible to measure the displacement fields of the interface. In our case, the displacement is calculated on a surface element close to the rupture zone. The devices required to use this technique are: a high speed camera, a computer and a light source (Figure 3a) synchronised at the start of the test with the measurement of the shear force through an acquisition box. This temporal synchronisation of 
the various signals (kinematic and mechanical) is ensured by a 'Synchrocam' electronic box that triggers all the acquisitions simultaneously (Chrysochoos, Wattrisse, Muracciole, \& El Kaïm, 2009).

By varying the normal force $N$, we can deduce the evolution of the shear strength $\sigma_{T}^{\max }$ compared to the confining stress $\sigma_{\mathrm{N}}$ applied. For this study, two experimental protocols were performed for direct shear tests:

- At different hydration times $\left(2,7,15,28\right.$ and 40 days) without confining stress $\left(\sigma_{N}=0 \mathrm{MPa}\right)$

- At 40 days of hydration time for different confining stresses $\left(\sigma_{N}=0 ; 0.5 ; 1\right.$ and $\left.1.5 \mathrm{MPa}\right)$.

\section{Experimental data}

We use the experimental results obtained by Jebli, Jamin, Malachanne, Garcia-Diaz, \& El Youssoufi (2018) of a shear test on a cement paste-aggregate composite at different stages of hydration $j$ (Figure $4 \mathrm{a}$ ) and for several confining stresses $\sigma_{\mathrm{N}}$ (Figure $4 \mathrm{~b}$ ). A quasi-brittle behaviour is observed without the softening part of the stress-strain curve. Without confining stress $\left(\sigma_{\mathrm{N}}=\right.$ $0 \mathrm{MPa}$ ), the results of the shear tests show an increase of the shear strength $\sigma_{\mathrm{T}}^{\max }$ (Figure $5 \mathrm{a}$ ), the rupture strain $\varepsilon_{r}$ (Figure $4 \mathrm{a}$ ) and the tangential modulus $E_{\mathrm{s}}$ (Figure $5 \mathrm{~b}$ ) with respect to the hydration time $j$. The shear modulus $E_{\mathrm{s}}$ was estimated using the slope of the linear part of the stress-strain curves. This increase is noticeable at the beginning of the cement paste hydration. Beyond 28 days, the shear strength $\sigma_{\mathrm{T}}^{\max }$ and the shear modulus $E_{\mathrm{s}}$ tend to stabilise.

At 40-day of hydration, the increasing of the confining stress $\sigma_{N}$ induces an increase of the shear strength $\sigma_{T}^{\max }$ (Figure $4 \mathrm{~b}$ ). However, the rupture strain $\varepsilon_{r}$ seems to be few affected by the value of the applied confining stress $\sigma_{N}$ (Figure $4 b$ ).

From these tests, we calculated the fracture energy as a function of the hydration time by the following relationship:

$$
w(j)=\frac{1}{2} \frac{\left(\sigma_{\mathrm{T}}^{\max }(j)\right)^{2}}{E_{\mathrm{s}}(j)}
$$

where $\sigma_{\mathrm{T}}^{\max }(j)$ is the shear strength and $E_{\mathrm{s}}(j)$ is the tangential modulus for a hydration time $j$. Figure 6a shows an increase of the fracture energy $w(j)$ with respect to the hydration of the samples; it tends to stabilise beyond 28 days of hydration.

There is a strong dependence of the mechanical response of cement paste-aggregate composite to the confining stress (Figure $6 \mathrm{~b}$ ). The application of the confining stress increases the
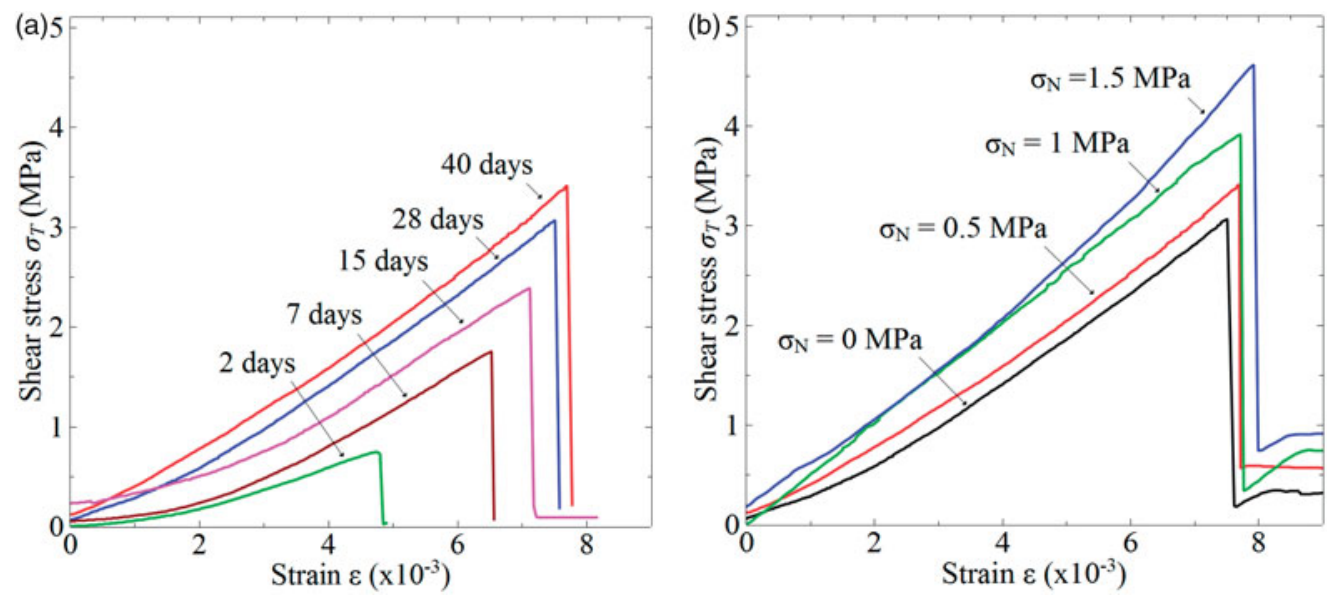

Figure 4. Stress-strain curves in direct shear tests during hydration (a) and stress-strain curves during direct shear test at 40day of hydration at different confining stresses (b) (Jebli, Jamin, Malachanne, Garcia-Diaz, \& El Youssoufi, 2018). 

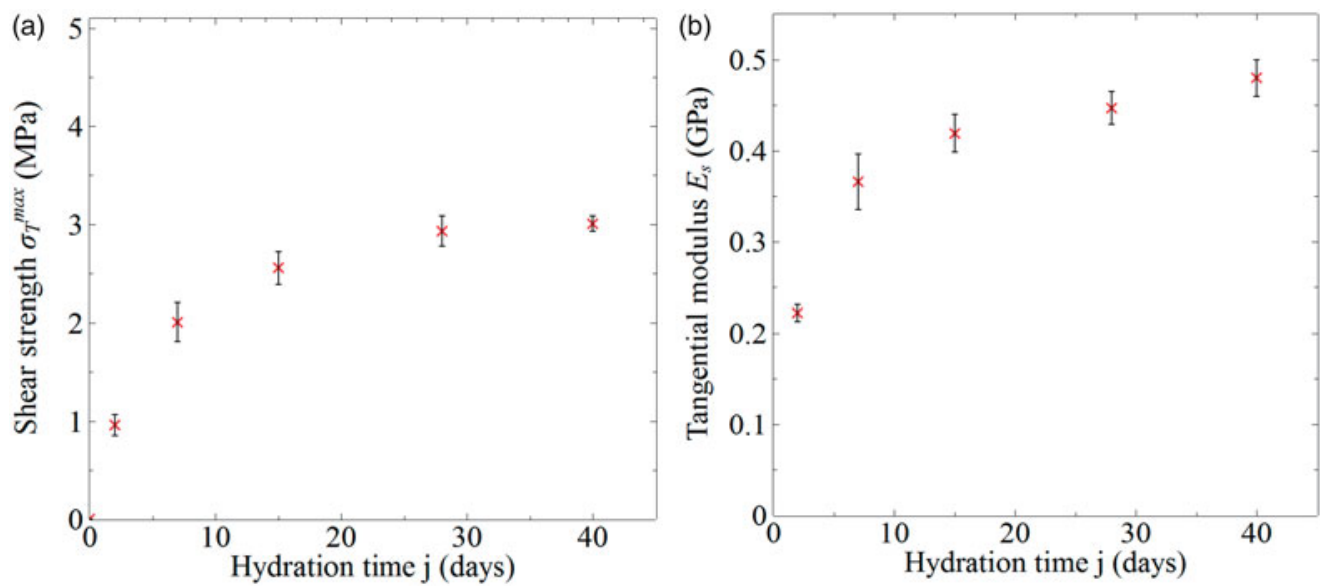

Figure 5. Evolution of the shear strength (a) and tangential modulus (b) as a function of the hydration time (Jebli, Jamin, Malachanne, Garcia-Diaz, \& El Youssoufi, 2018).
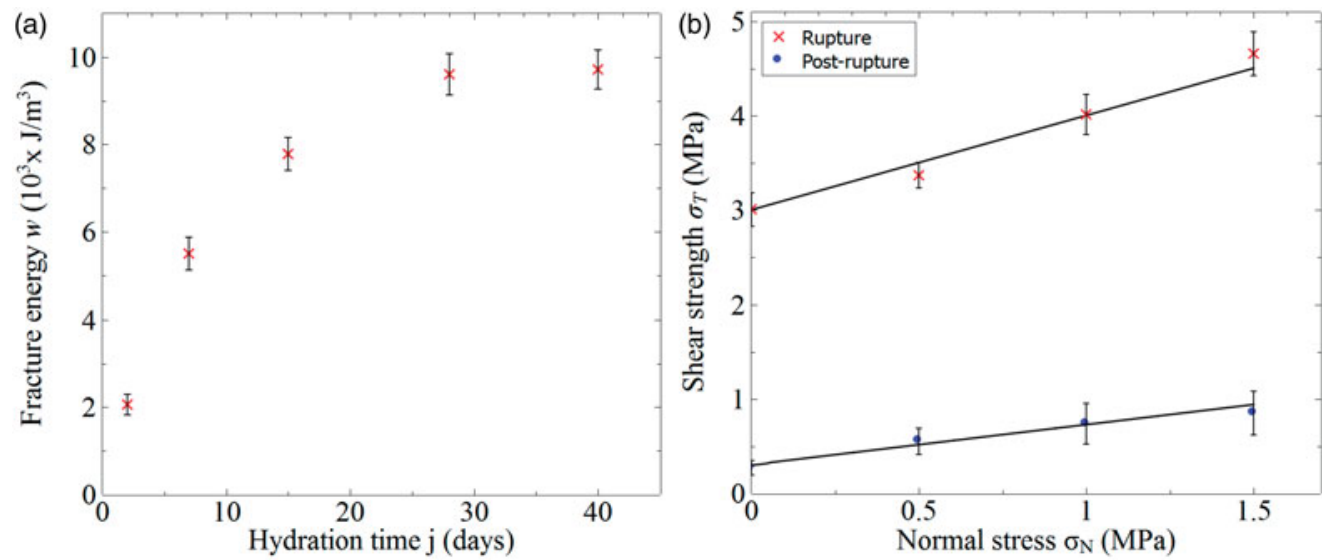

Figure 6. Evolution of the fracture energy as a function of hydration time (Jebli, Jamin, Malachanne, Garcia-Diaz, \& El Youssoufi, 2018) (a) and Mohr-Coulomb criterion at rupture and post-rupture for 40-day of hydration (b).

shear strength (peak value). This evolution of shear strength according to the confining stress is used to calculate the internal friction angle and cohesion according to Mohr-Coulomb criterion. We noticed a linear evolution of the shear strength with the increase of the confining stresses. According to Mohr-Coulomb's law, the rupture criterion is defined by the following relationship:

$$
\sigma_{\top}^{\max }=\sigma_{\mathrm{N}} \times \tan \phi+C
$$

With $\sigma_{\top}^{\max }$ is the stress strength, $\mu=\tan \phi$ is the friction coefficient and $C$ is the cohesion. And for post-rupture is defined as follow:

$$
\sigma_{\mathrm{T}}^{\text {res }}=\sigma_{\mathrm{N}} \times \tan \phi_{\text {res }}+C_{\text {res }}
$$

where $\sigma_{\mathrm{T}}^{\text {res }}$ is the residual stress, $\mu_{\text {res }}=\tan \phi_{\text {res }}$ is the residual friction coefficient and $C_{\text {res }}$ is the residual cohesion. From these results, the objective is to identify the mechanical properties of the cement paste-aggregate interface by the use of a numerical tool based on cohesive zone model. 


\section{Numerical identification}

A finite element model of the composite presented in the previous sections, is realised by considering a non-linear interaction at the interface between the phases. A cohesive zone model (CZM) was used to describe the evolution of the damage between two initially adherent bodies.

\subsection{Cohesive zone model}

The concept of Cohesive Zone Models (CZM) was introduced by Dugdale (1960) and Barenblatt (1962) in the 1960s. The first cohesive zone models describe only the evolution of the cohesive tensile stress as a function of the normal displacement jump. Around the 1970s, models were enriched to account for the evolution of cohesive tangential stress as a function of the tangential displacement jump. The shear was first introduced in the cohesive zone models by Ida (1972) and Palmer and Rice (1973). The work of Fremond $(1985,1987)$ has introduced the notion of adhesion (with a variable describing the intensity of adhesion) and unilateral contact. The model given by Tvergaard (1990) proposes a post-decohesion Coulomb's friction. The principle of treating the cohesive zone model simultaneously with frictional contact has been proposed in the work of Raous, Cangemi, and Cocu (1999) and Bretelle, Cocou, and Monerie (2001). There are different forms of cohesive laws: polynomial, trapezoidal, bilinear, echelons, etc. (Perales, 2005). The cohesive law adopted in this work, is an extension of the law presented in (Perales, Bourgeois, Chrysochoos, \& Monerie, 2008) which takes into account the mixed modes (Bisoffi-Sauve, Morel, \& Dubois, 2019).

In this section, we will limit ourselves to the presentation of the main equations of the cohesive zone model in two dimensions, as well as its parameters. The model considers non-penetration between the two bodies in contact; the adhesion is defined here in the sense of a resistance to the separation expressing the process of rupture (Perales, 2005); the adhesion force $\vec{R}$ between the two bodies is decomposed into a normal component $R_{\mathrm{N}}$ and a tangential component $R_{\mathrm{T}}$ such that $\vec{R}=R_{\mathrm{N}} \vec{n}+R_{\mathrm{T}} \vec{t}$.

The displacement jump is decomposed as follows:

$$
[\vec{u}]=\left[\left|u_{\mathrm{N}}\right|\right] \vec{n}+\left[\left|u_{\mathrm{T}}\right|\right] \vec{t} \quad \text { with } \quad\left[\left|u_{\mathrm{N}}\right|\right]=\vec{u} \cdot \vec{n} \quad \text { and } \quad\left[\left|u_{\mathrm{T}}\right|\right]=\vec{u} \cdot \vec{t}
$$

Moreover, a variable $\beta$ is introduced to represent the intensity of adhesion (Fremond, 1987) which evolves during the loading and which is linked to a damage parameter $D$ (Monerie \& Acary, 2001) so that:

$$
\beta=1-D
$$

- $\beta=1$ : total adhesion.

- $0<\beta<1$ ! ! : partial adhesion.

- $\beta=0$ : No adhesion and in this case, we recover the Signorini Coulomb condition.

Unilateral condition (Signorini condition) with adhesion:

$$
\left[\left|u_{N}\right|\right] \geq 0 \text { and }\left(R_{N}+R_{N}^{\text {adh }}\right) \geq 0
$$

Or it can be written in the form of a condition of complementarity.

$$
\left[\left|u_{N}\right|\right] \cdot\left(R_{N}+R_{N}^{\text {adh }}\right)=0
$$


Coulomb's friction with adhesion: Coulomb friction is characterised by a threshold that depends on the normal reaction.

$$
\begin{gathered}
\left|R_{\mathrm{T}}+R_{\mathrm{T}}^{\text {adh }}\right|<\mu(\beta) \cdot\left(R_{\mathrm{N}}+R_{\mathrm{N}}^{\text {adh }}\right) \Rightarrow V_{\mathrm{T}}=0 \quad: \text { stick. } \\
\left|R_{\mathrm{T}}+R_{\mathrm{T}}^{\text {adh }}\right|=\mu(\beta) \cdot\left(R_{\mathrm{N}}+R_{\mathrm{N}}^{\text {adh }}\right) \Rightarrow V_{\mathrm{T}}=-\lambda \cdot \frac{\left(R_{\mathrm{T}}+R_{\mathrm{T}}^{\text {adh }}\right)}{\left\|! ! R_{\mathrm{T}}+R_{\mathrm{T}}^{\text {adh }} ! !\right\|}, \quad \lambda>0 \quad: \text { slip }
\end{gathered}
$$

with

$$
\begin{gathered}
R^{\mathrm{adh}}=K(\beta)[|u|] \\
K(\beta)=\beta\left(C_{\mathrm{N}} n \otimes n+C_{\mathrm{T}} \frac{\left(u_{\mathrm{T}} \otimes u_{\mathrm{T}}\right)}{\left\|! ! u_{\mathrm{T}}\right\|^{2}}\right)
\end{gathered}
$$

where $C_{\mathrm{N}}$ and $C_{\mathrm{T}}$ are the normal and tangential interfacial stiffnesses.

To solve this problem, we need a law of evolution of $\beta$ which depends on parameters like the fracture energy, the critical stress, etc. (Perales, 2005). The evolution of $\beta$ makes it possible to take into account the softening of the surface behaviour. the evolution of the adhesion intensity, taking into account the irreversibility of the behaviour when the interface is partially damaged is governed by the following system.

$$
\left\{\begin{array}{l}
\beta=\min \left(g\left([|u|]^{\max }\right), g([|u|])\right) \\
g(x)=\left\{\begin{array}{l}
\beta_{0} \text { if }\|! ! x ! !\|<\delta_{c}, \\
\beta_{0} \frac{3 \delta_{\mathrm{c}}-\|! ! x ! !\|}{\delta_{\mathrm{c}}+\|! ! x ! !\|} \\
0 \text { else }
\end{array} \text { if } \delta_{\mathrm{c}} \leq\|! ! x ! !\| \leq 3 \delta_{\mathrm{c}}\right.
\end{array}\right.
$$

with:

$$
\delta_{\mathrm{c}}=\sqrt{\frac{w}{9-4 \ln 4}\left(\frac{1}{C_{\mathrm{N}}}+\frac{1}{C_{\mathrm{T}}}\right)}
$$

the decreasing function $g$ describes the softening of adhesion, $0 \leq \beta_{0} \leq 1$ is an initial damage and $[|u|]^{\max }$ is the highest value reached by the displacement jump $[|u|]$.

\subsection{Model parameters limited to shear test case}

The cohesive zone model defined in the previous paragraph is based on a cohesive law which parameters are the following:

- $\quad C_{\mathrm{N}}$ and $C_{\mathrm{T}}$ the normal and tangential interfacial stiffnesses.

- $\sigma_{\mathrm{T}}^{\max }$ the critical cohesive stress.

- $\quad w$ the fracture energy.

- $\mu_{\text {res }}$ the residual coefficient of friction.

The Figure 7 illustrates the form of the cohesive law on which this study is based, representing the response of a $2 \mathrm{D}$ interface model during a shear test with:

1. Normal displacement jump $\left[\left|u_{N}\right|\right]=0$.

2. Constant normal reaction $R_{N}$.

- For $u_{\mathrm{T}}=0$ and in the presence of friction, an elastic tangential displacement occurs only if the slip limit is reached. 


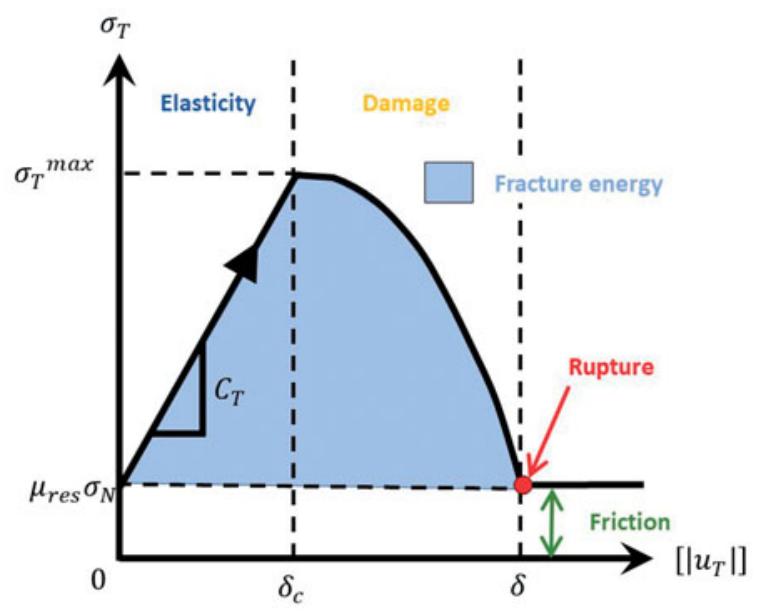

Figure 7. Tangential cohesive law in 2D.

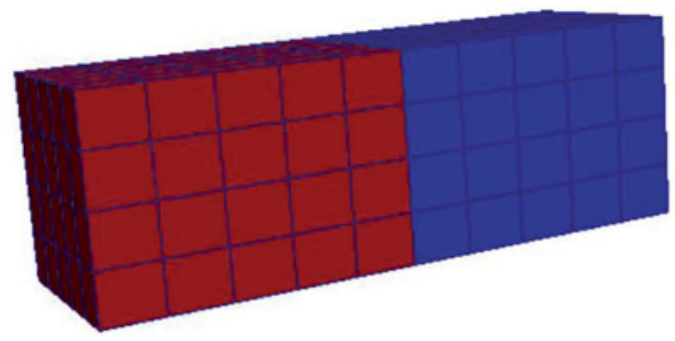

Figure 8. Mesh Geometry.

- For $0<\left[\left|u_{T}\right|\right]<\delta_{C}$, the behaviour is linear. The slope of the curve is equal to $C_{T}$.

- For $\delta_{c} \leq\left[\left|u_{T}\right|\right] \leq \delta$ : the interface is damaged and $\beta$ follows the law (12).

- For $\left[\left|u_{T}\right|\right]>\delta$, the adhesive part is cancelled and the Coulomb's friction behaviour occurs.

It should be noted that friction force is activated only if normal confining force is applied $\left(R_{\mathrm{N}}>0\right)$. The computation of the interaction (here the CZM) are computed using the NSCD method implemented in LMGC90 software (Dubois, Acary, \& Jean, 2018). This method was initially developed by Jean (1999) and Moreau (1999) and proposes a formalism adapted to the modelling of dynamical systems with frictional contacts. The NSCD method makes it possible to solve unilateral contact with Coulomb's friction without regularisation or penalisation. Few modifications (Jean, Acary, \& Monerie, 2001) made it possible to take into account Cohesive Zone Models.

\subsection{Numerical modelling of the shear test}

\subsubsection{Discretisation}

The cohesive zone model is implemented in the LMGC90 platform (Dubois et al., 2011). This open source platform is developed at LMGC (University of Montpellier and CNRS). A three-dimensional finite element model of the composite has been realised. The geometry was carried out on GMSH and meshed with regular hexahedron elements (Figure 8). The mesh element size used is $1 \mathrm{~mm} \times 1 \mathrm{~mm} \times 1 \mathrm{~mm}$. The damage is carried by the cohesive law at the interface. The local behaviour of the composite is decomposed into a softening part describing the damage 
through a cohesive law and an elastic part taken into account by the bulk part. The time step is calibrated according to the material parameters and the mesh size.

At each time step, a contact detection is performed, the rupture occurs when the cohesion is lost between the two materials $(\beta=0)$. A mesh sensitivity analysis has been performed and did not show a significant influence on numerical results. Thus, a coarse meshing has been chosen to reduce calculation time.

\subsubsection{Numerical simulation}

In order to faithfully reproduce the experimental shear test, the boundary conditions shown in Figure 9 were applied to the finite element model. Since the cement block was embedded a displacement was applied to all the nodes of the upper face of the aggregate. $N$ represents a confining force applied to the aggregate. To calibrate the cohesive law at each hydration stage (j) and each confinement stress, shear strength $\sigma_{\top}^{\max }(j)$, the displacement jump at rupture $\left[\left|u_{\top}^{\max }(j)\right|\right]$ and the residual friction $\mu_{\text {res }}$ were taken into account with reference to the experimental results (Jebli, Jamin, Malachanne, Garcia-Diaz, \& El Youssoufi, 2018). Its value $\mu_{\text {res }}=0.4$ was identified from the post-peak part of the experimental curves for an hydration time equal to 40 days. From the resistance and the displacement jump at rupture, the fracture energy $w(j)$ has been calculated by the following formula:

$$
w(j)=\frac{1}{2} \sigma_{\top}^{\max }(j) \times \delta
$$

These elements $\left(\sigma_{T}^{\max }(j), w(j)\right.$ et $\left.\mu_{\text {res }}\right)$ have been used in LMGC90. The normal and tangential interfacial stiffnesses were determined as follows:

$$
C_{\mathrm{N}}(j)=C_{\mathrm{T}}(j)=\frac{1}{2} \frac{\left(\sigma_{\mathrm{T}}^{\max }(j)\right)^{2}}{w(j)}
$$

The input parameters of the cohesive law are given, for each time of hydration, by Table 3 and, for each confining stress, by Table 4 .

\section{Results and discussions}

A numerical identification, based on experimental shear tests results (Jebli, Jamin, Malachanne, Garcia-Diaz, \& El Youssoufi, 2018), was carried out. The Figure 10 shows the numerical/experimental calibration of the curves for different hydration stages and several confining stresses.

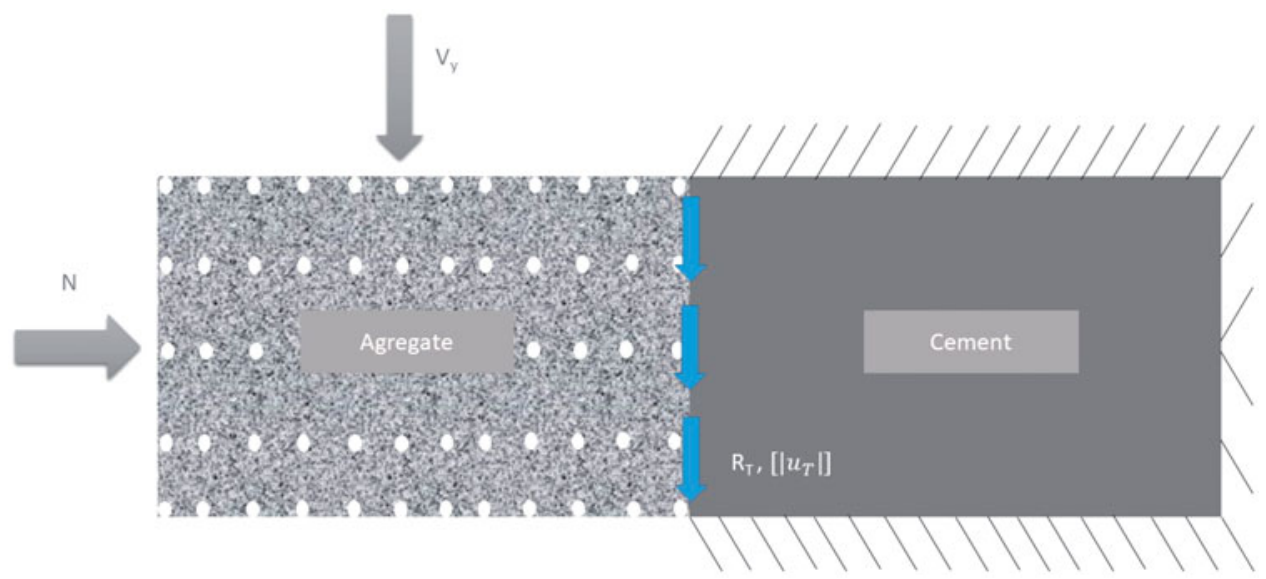

Figure 9. A graph illustrating boundary conditions and applied forces. 
Table 3. Cohesive parameters at different time of hydration.

\begin{tabular}{lccc}
\hline Days $(\mathrm{j})$ & Stress $($ mode II) $(\mathrm{MPa})$ & Fracture energy $\left(\mathrm{J} / \mathrm{m}^{2}\right)$ & Tangential stiffness $\left(10^{4} \mathrm{MPa}\right)$ \\
\hline 2 & 0.75 & 12.74 & 2.18 \\
7 & 1.75 & 40.82 & 3.77 \\
15 & 2.39 & 69.57 & 4.10 \\
28 & 3.06 & 98.64 & 4.76 \\
\hline
\end{tabular}

Table 4. Cohesive parameters for different confining stresses at $40 \mathrm{j}$ of hydration.

\begin{tabular}{lccc}
\hline Confining stress $(\mathrm{MPa})$ & Stress $(\mathrm{MPa})$ & Fracture energy $\left(\mathrm{J} / \mathrm{m}^{2}\right)$ & Tangential stiffness $\left(10^{4} \mathrm{MPa}\right)$ \\
\hline 0 & 3.06 & 98.64 & 4.76 \\
0.5 & 3.42 & 113.41 & 5.13 \\
1 & 3.91 & 151.03 & 5.61 \\
1.5 & 4.62 & 157.98 & 6.74 \\
\hline
\end{tabular}
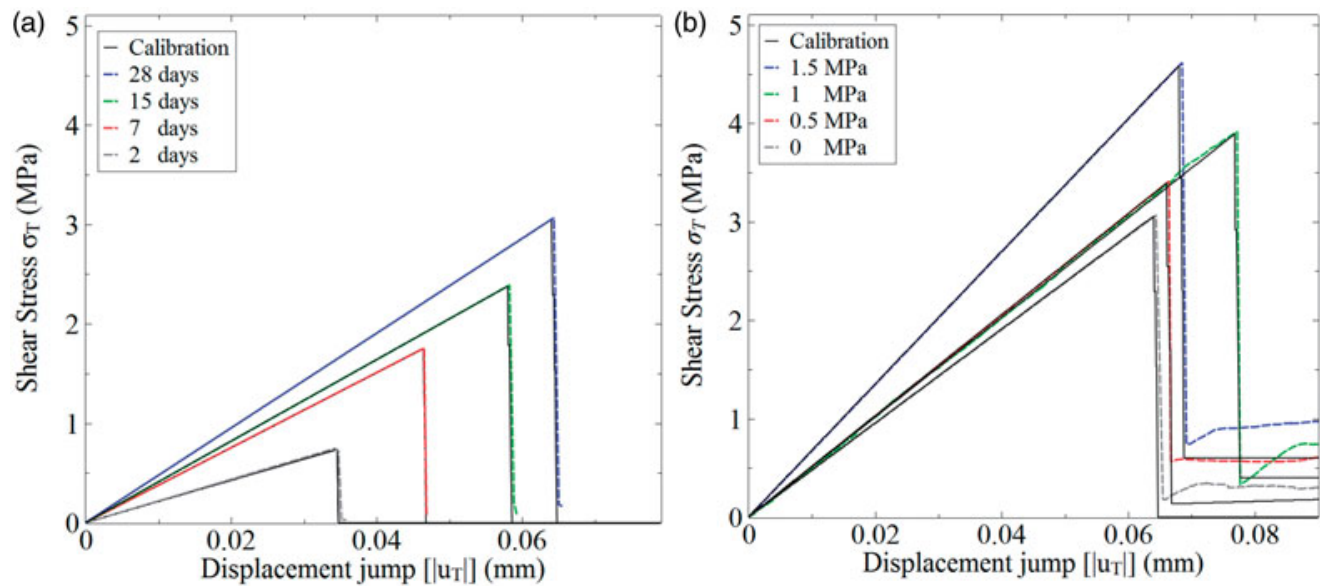

Figure 10. Calibration of the simulation results on LMGC90 using a cohesive zone model to experimental shear test results for different hydration times (a) and different confining stresses (b).

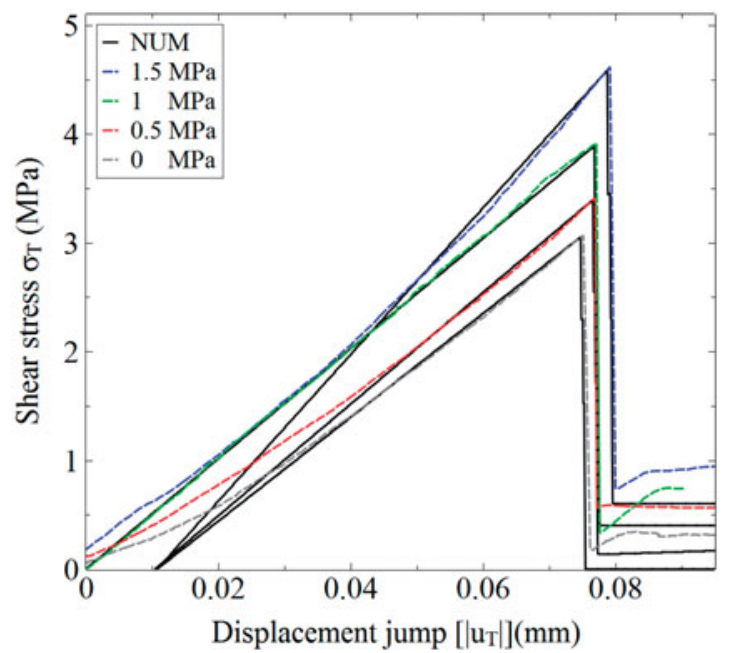

Figure 11. Simulation results on LMGC90 using a cohesive zone model compared to experimental results of the shear test for different confining stresses.

First, we remove the sample's placement part that gives a non-linear aspect to the curve at the beginning of loading. This is done by drawing the tangent line to the curve that passes through 

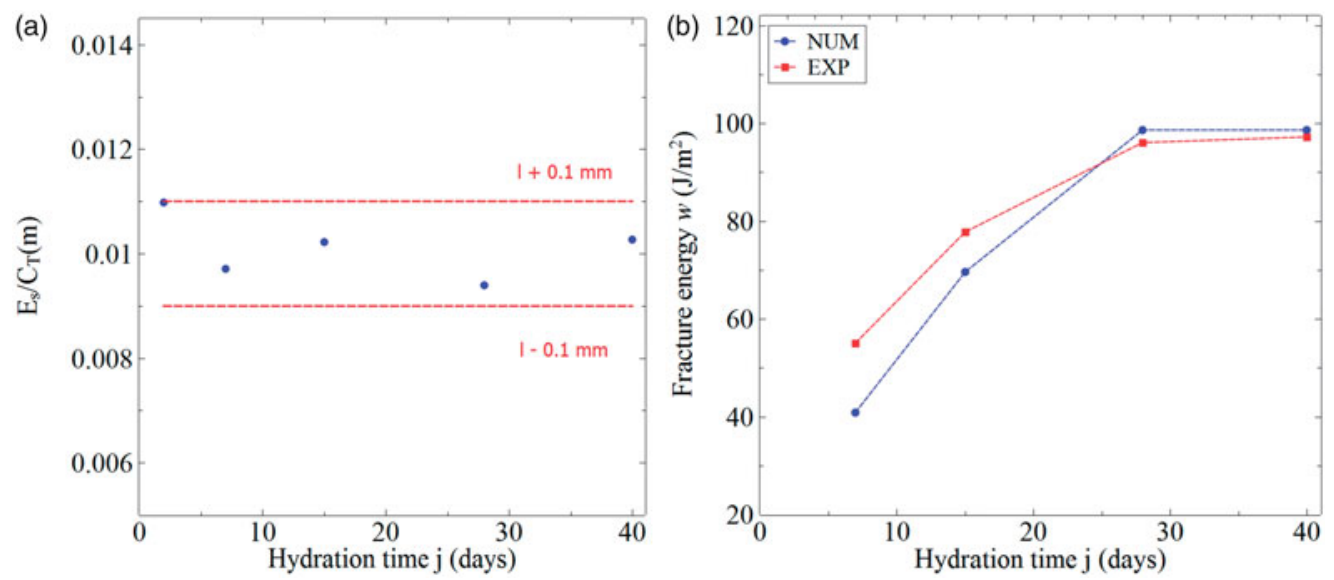

Figure 12. Ratio of the shear modulus $E_{\mathrm{s}}$ and the stiffness $C_{\mathrm{T}}$ of the cohesive law for different hydration stages (a) and comparison of the experimental and numerical fracture energy during hardening (b).

the shear strength and that intersects the horizontal axis at a non-zero displacement jump value. Second, the curve was moved until it passes through the origin. Figure 11 shows a comparison between numerical and experimental results for several confining stresses. For the pre-peak part of the curves and for $\sigma_{\mathrm{N}}=0,0.5$ and $1.5 \mathrm{MPa}$, an offset of $0.0108 \mathrm{~mm}$ occurs at the displacement jump. This latter results from the corrections made on the experimental curves in order to avoid the influence of the sample's placement and to determine the correct input parameters of the cohesive law.

After the rupture, we observe a sudden stress drop with absence of the softening part. Numerically, this corresponds a loss of cohesion between the cement paste and the aggregate. For the post-rupture part, the cement paste-aggregate interface is totally damaged and the contact remaining at the end of the test is purely frictional with a $\mu_{\text {res }} \sigma_{N}$ value (residual stress) and which is observed on the result of the numerical model. However, experimental results present always an offset compared to the numerical one, this offset is of a constant value on all the curves. It is equal to the value of a residual cohesion $C_{\text {res }}$ that has been determined on the curve of Figure $6 \mathrm{~b}$. Indeed, after the rupture, this cohesion should be cancelled and this shift can be explained by the fact that the experimental tests was not enough extended to study the postrupture part. Currently a new device is in use to correct these experimental results.

According to the Figure $12 \mathrm{a}$, the ratio of the experimental tangential modulus $E_{\mathrm{s}}$ to the stiffness of the cohesive law $C_{T}$ shows values in the interval $[1-0.01 \mathrm{~mm}, 1+0.01 \mathrm{~mm}]$ with $\mathrm{I}=10 \mathrm{~mm}$ as the width of the sample. An increase in the fracture energy $w$ is observed with an increase in the hydration time (Figure 12b), which progressively reaches a constant value beyond 28 days of hydration. The values of the experimental and numerical fracture energy are comparable and the offset tends to cancel with hardening.

All these results of identification thus that made for the case of the tensile test will be exploitable to model the mechanical behaviour of the mortar at different stages of hydration on a mesoscopic and/or macroscopic scale taking into account the interface cement paste-aggregate. The cement paste-aggregate interface in the case of a compression test is solicited in mixed mode.

\section{Conclusion and perspectives}

The experimental results showed that the most fragile zone is located at the concrete the interface. This interface is thin and has a greater porosity than the cement matrix. This characteristic seems to considerably affects the mechanical properties of concrete, which effect is noticeable 
from the initiation to the propagation of the crack in the less resistant zones within the concrete. These preliminary results present a first approach to characterise the mechanical properties of the interface with original experimental tools. The simulation of shear tests on a composite material using a cohesive zone model has made possible to identify the mechanical parameters of the bond 'cement paste - limestone aggregate'. This identification was carried out for different hydration times and for different confinement stresses. The numerical results show that the cohesive zone model is able to describe this type of mechanical behaviour. The locally identified parameters are preliminary results for the comprehension of more global behaviour on macroscopic sample or on structure.

\section{Notation}

$\beta \quad$ intensity of adhesion

$C \quad$ cohesion

$C_{N} \quad$ normal interfacial stiffness

$C_{\mathrm{T}} \quad$ tangential interfacial stiffness

$C_{\text {res }}$ residual cohesion

$D$ damage parameter

$\delta_{\mathrm{c}} \quad$ critical displacement

$\sigma_{\mathrm{N}} \quad$ confining stress

$\sigma_{\mathrm{T}}^{\max } \quad$ Critical cohesive stress

$g$

$R^{\text {adh }}$

$R_{\mathrm{N}}^{\text {adh }}$

$R_{\top}{ }^{\text {adh }}$

$u_{N} \quad$ normal displacements

$u_{T} \quad$ tangential displacements

$[|u|] \quad$ displacement jump

$w \quad$ fracture energy

$\mu \quad$ friction coefficient

$\mu^{\text {res }} \quad$ residual friction coefficient

\section{Disclosure statement}

No potential conflict of interest was reported by the authors.

\section{References}

Alfano, G., \& Sacco, E. (2006). Combining interface damage and friction in a cohesive-zone model. International Journal for Numerical Methods in Engineering, 68(5), 542-582. doi:10.1002/nme.1728

Barenblatt, G. I. (1962). The mathematical theory of equilibrium cracks in brittle fracture. In Dryden H. L. and von Karman TH. (Eds) Advances in applied mechanics (vol. 7, pp. 55-129). Amsterdam: Elsevier.

Bernard, F., \& Kamali-Bernard, S. (2015). Numerical study of itz contribution on mechanical behavior and diffusivity of mortars. Computational Materials Science, 102, 250-257. doi:10.1016/j.commatsci.2015.02.016

Bisoffi-Sauve, M., Morel, S., \& Dubois, F. (2019). Modelling mixed mode fracture of mortar joints in masonry buildings. Engineering Structures, 182, 316-330. doi:10.1016/j.engstruct.2018.11.064

Bretelle, A.-S., Cocou, M., \& Monerie, Y. (2001). Unilateral contact with adhesion and friction between two hyperelastic bodies. International Journal of Engineering Science, 39(18), 2015-2032. doi:10.1016/S0020-7225(01)00052-0

Chrysochoos, A., Wattrisse, B., Muracciole, J.-M., \& El Kaïm, Y. (2009). Fields of stored energy associated with localized necking of steel. Journal of Mechanics of Materials and Structures, 4(2), 245-262. doi:10.2140/ jomms.2009.4.245

Diamond, S. (2001). Considerations in image analysis as applied to investigations of the itz in concrete. Cement and Concrete Composites, 23(2-3), 171-178. doi:10.1016/S0958-9465(00)00085-8

Diamond, S., \& Huang, J. (2001). The itz in concrete-A different view based on image analysis and SEM observations. Cement and Concrete Composites, 23(2-3), 179-188. doi:10.1016/S0958-9465(00)00065-2 
Diamond, S., Mindess, S., \& Lovell, J. (1982). On the spacing between aggregate grains in concrete and the dimension of the aureole of transition. International RILEM Colloquium, Liaisons Pastes de Ciment/Materiaux Associates, C42-C46.

Dubois, F., Acary, V., \& Jean, M. (2018). The Contact Dynamics method: A nonsmooth story. Comptes Rendus Mécanique, 346(3), 247-262. doi:10.1016/j.crme.2017.12.009

Dubois, F., Jean, M., Renouf, M., Mozul, R., Martin, A., \& Bagneris, M. (2011). LMGC90. In Colloque National en Calcul des Structures.

Dugdale, D. S. (1960). Yielding of steel sheets containing slits. Journal of the Mechanics and Physics of Solids, 8(2), 100-104. doi:10.1016/0022-5096(60)90013-2

Erdem, S., Dawson, A., \& Thom, N. (2012a). Impact load-induced micro-structural damage and micro-structure associated mechanical response of concrete made with different surface roughness and porosity aggregates. Cement and Concrete Research, 42(2), 291-305. doi:10.1016/j.cemconres.2011.09.015

Erdem, S., Dawson, A., \& Thom, N. (2012b). Influence of the micro- and nanoscale local mechanical properties of the interfacial transition zone on impact behavior of concrete made with different aggregates. Cement and Concrete Research, 42(2), 447-458. doi:10.1016/j.cemconres.2011.11.015

Fouchal, F., Lebon, F., \& Titeux, I. (2009). Contribution to the modelling of interfaces in masonry construction. Construction and Building Materials, 23(6), 2428-2441. doi:10.1016/j.conbuildmat.2008.10.011

Fremond, M. (1985). Contact unilatéral avec adhérence. In Del Pierro G. and Maceri F. (Eds) Unilateral problems in structural analysis (pp. 57-79). New York: Springer.

Fremond, M. (1987). Contact unilatéral avec adhérence une théorie du premier gradient. In Del Pierro G. and Maceri F. (Eds) Unilateral problems in structural analysis-2 (pp. 117-137). New York: Springer.

Fremond, M., \& Nedjar, B. (1996). Damage, gradient of damage and principle of virtual power. International Journal of Solids and Structures, 33(8), 1083-1103. doi:10.1016/0020-7683(95)00074-7

Gangnant, A., Saliba, J., La Borderie, C., \& Morel, S. (2016). Modeling of the quasibrittle fracture of concrete at meso-scale: Effect of classes of aggregates on global and local behavior. Cement and Concrete Research, 89, 35-44.

Grondin, F., \& Matallah, M. (2014). How to consider the interfacial transition zones in the finite element modelling of concrete? Cement and Concrete Research, 58, 67-75. doi:10.1016/j.cemconres.2014.01.009

Ida, Y. (1972). Cohesive force across the tip of a longitudinal-shear crack and Griffith's specific surface energy. Journal of Geophysical Research, 77(20), 3796-3805. doi:10.1029/JB077i020p03796

Jean, M. (1999). The non-smooth contact dynamics method. Computer Methods in Applied Mechanics and Engineering, 177(3-4), 235-257. doi:10.1016/S0045-7825(98)00383-1

Jean, M., Acary, V., \& Monerie, Y. (2001). Non-smooth contact dynamics approach of cohesive materials. Philosophical Transactions of the Royal Society of London. Series A: Mathematical, Physical and Engineering Sciences, 359(1789), 2497-2518. doi:10.1098/rsta.2001.0906

Jebli, M., Jamin, F., Malachanne, E., Garcia-Diaz, E., \& El Youssoufi, M. S. (2018). Experimental characterization of mechanical properties of the cement-aggregate interface in concrete. Construction and Building Materials, 161, 16-25. doi:10.1016/j.conbuildmat.2017.11.100

Kamali-Bernard, S., Keinde, D., \& Bernard, F. (2014). Effect of aggregate type on the concrete matrix/aggregates interface and its influence on the overall mechanical behavior. A numerical study. In Fujimoto K., Kawamor $\mathrm{SH}$, Cordier S. and Tessier F. (Eds) Key engineering materials (Vol. 617, pp. 14-17). doi:10.4028/www.scientific.net/ KEM.617.14

Ke, Y., Ortola, S., Beaucour, A., \& Dumontet, H. (2010). Identification of microstructural characteristics in lightweight aggregate concretes by micromechanical modelling including the interfacial transition zone (itz). Cement and Concrete Research, 40(11), 1590-1600. doi:10.1016/j.cemconres.2010.07.001

Keinde, D., Kamali-Bernard, S., Bernard, F., \& Cisse, I. (2014). Effect of the interfacial transition zone and the nature of the matrix-aggregate interface on the overall elastic and inelastic behavior of concrete under compression: $A$ 3D numerical study. European Journal of Environmental and Civil Engineering, 18(10), 1167-1176. doi:10.1080/ 19648189.2014.896757

Lutz, M. P., Monteiro, P. J., \& Zimmerman, R. W. (1997). Inhomogeneous interfacial transition zone model for the bulk modulus of mortar. Cement and Concrete Research, 27(7), 1113-1122. doi:10.1016/S0008-8846(97)00086-0

Malachanne, E., Jebli, M., Jamin, F., Garcia-Diaz, E., \& El Youssoufi, M. S. (2018). A cohesive zone model for the characterization of adhesion between cement paste and aggregates. Construction and Building Materials, 193, 64-71. doi:10.1016/j.conbuildmat.2018.10.188

Monerie, Y., \& Acary, V. (2001). Formulation dynamique d'un modèle de zone cohésive tridimensionnel couplant endommagement et frottement. Revue Européenne Des Éléments Finis, 10(2-4), 489-503. doi:10.1080/ 12506559.2001.11869264

Moreau, J. J. (1999). Numerical aspects of the sweeping process. Computer Methods in Applied Mechanics and Engineering, 177(3-4), 329-349. doi:10.1016/S0045-7825(98)00387-9

Neubauer, C., Jennings, H., \& Garboczi, E. (1996). A three-phase model of the elastic and shrinkage properties of mortar. Advanced Cement Based Materials, 4(1), 6-20. doi:10.1016/S1065-7355(96)90058-9 
Ollivier, J., \& Grandet, J. (1982). Sequence of formation of the aureole of transition. In Colloque International Sur Les Liaisons Pâtes de Ciment-Matériaux Associés (pp. 14-22). Toulouse, France.

Ollivier, J., Maso, J., \& Bourdette, B. (1995). Interfacial transition zone in concrete. Advanced Cement Based Materials, 2(1), 30-38. doi:10.1016/1065-7355(95)90037-3

Palmer, A. C., \& Rice, J. R. (1973). The growth of slip surfaces in the progressive failure of over-consolidated clay. Proceedings of the Royal Society A, 332(1591), 527-548. doi:10.1098/rspa.1973.0040

Perales, F. (2005). Fissuration des matériaux à gradient de propriétés. Application au Zircaloy hydruré (Unpublished doctoral dissertation). Université Montpellier II-Sciences et Techniques du Languedoc.

Perales, F., Bourgeois, S., Chrysochoos, A., \& Monerie, Y. (2008). Two field multibody method for periodic homogenization in fracture mechanics of nonlinear heterogeneous materials. Engineering Fracture Mechanics, 75(11), 3378-3398. doi:10.1016/j.engfracmech.2007.07.017

Raous, M. (2011). Interface models coupling adhesion and friction. Comptes Rendus Mécanique, 339(7-8), 491-501. doi:10.1016/j.crme.2011.05.007

Raous, M., Cangemi, L., \& Cocu, M. (1999). A consistent model coupling adhesion, friction, and unilateral contact. Computer Methods in Applied Mechanics and Engineering, 177(3-4), 383-399. doi:10.1016/S0045-7825(98)00389-2

Shuguang, L., \& Qingbin, L. (2015). Method of meshing ITZ structure in 3D meso-level finite element analysis for concrete. Finite Elements in Analysis and Design, 93, 96-106. doi:10.1016/j.finel.2014.09.006

Talon, C., \& Curnier, A. (2003). A model of adhesion coupled to contact and friction. European Journal of Mechanics - A/Solids, 22(4), 545-565. doi:10.1016/S0997-7538(03)00046-9

Tvergaard, V. (1990). Effect of fibre debonding in a whisker-reinforced metal. Materials Science and Engineering: $A$, 125(2), 203-213. doi:10.1016/0921-5093(90)90170-8

Vargas, P., Restrepo-Baena, O., \& Tobón, J. I. (2017). Microstructural analysis of interfacial transition zone (ITZ) and its impact on the compressive strength of lightweight concretes. Construction and Building Materials, 137, 381-389. doi:10.1016/j.conbuildmat.2017.01.101

Wattrisse, B., Chrysochoos, A., Muracciole, J.-M., \& Némoz-Gaillard, M. (2001). Analysis of strain localization during tensile tests by digital image correlation. Experimental Mechanics, 41(1), 29-39. doi:10.1007/BF02323101

Wittmann, F. (1983). Structure of concrete with respect to crack formation. Fracture Mechanics of Concrete, $43(5), 6$.

Zhou, C., Li, K., \& Ma, F. (2014). Numerical and statistical analysis of elastic modulus of concrete as a three-phase heterogeneous composite. Computers and Structures, 139, 33-42. doi:10.1016/j.compstruc.2014.04.007 